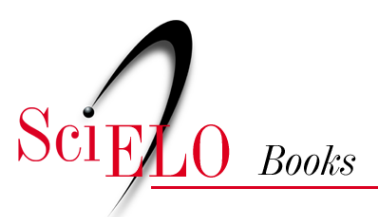

\title{
20 Tribo Inuleae Cass.
}

\author{
Marcelo Monge \\ Arne A. Anderberg \\ João Semir
}

MONGE, M., ANDERBERG, A.A., and SEMIR, J. Tribo Inuleae Cass. In: ROQUE, N. TELES, A.M., and NAKAJIMA, J.N., comp. A família Asteraceae no Brasil: classificação e diversidade [online]. Salvador: EDUFBA, 2017, pp. 153-159. ISBN: 978-85-232-1999-4.

https://doi.org/10.7476/9788523219994.0022.

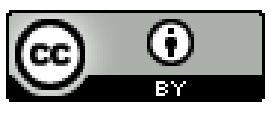

All the contents of this work, except where otherwise noted, is licensed under a Creative Commons Attribution 4.0 International license.

Todo o conteúdo deste trabalho, exceto quando houver ressalva, é publicado sob a licença Creative Commons Atribição $\underline{4.0}$. 


\title{
TRIBO INULEAE CASS.
}

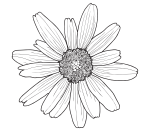 \\ Marcelo Monge \\ Arne A. Anderberg \\ João Semir
}

Inuleae foi estabelecida por Cassini (1819) como a $12^{\mathrm{a}}$ tribo de Asteraceae. Posteriormente, alguns autores propuseram novas classificações para a família incluindo a tribo Inuleae (CANDOLLE, 1836; HOFFMANN, 1890; LESSING, 1832); entretanto, foi a classificação de Bentham (1873) que perdurou por mais de um século. Bentham (1873), em seu trabalho, reorganizou a tribo Inuleae em 9 subtribos, baseando-se na sexualidade das flores, morfologia dos ramos do estilete e presença ou ausência de páleas no receptáculo.

Quase um século depois, Merxmüller, Leins e Roessler (1977) discutiram que as classificações propostas para a tribo não refletiam grupos naturais, pois estas apresentavam grande sobreposição de caracteres diagnósticos e outras incongruências. Assim, Merxmüller, Leins e Roessler (1977) recircunscreveram Inuleae com base nos seguintes caracteres diagnósticos: presença de anteras caudadas, às vezes sagitadas; flores com corola amarela, com heterogamia predominante; ramos do estilete agudos; pápus plumoso. Esses mesmos autores também propuseram 3 subtribos: Inulinae s.l., Gnaphaliinae s.l. e Athrixiinae s.l. Por fim, Merxmüller, Leins e Roessler (1977) reconheceram que, mesmo no sistema proposto, ainda persistiam problemas de delimitação nas subtribos e em alguns gêneros.

Bremer (1987), ao estudar as relações filogenéticas da família Asteraceae com base em dados morfológicos, concluiu que a tribo Inuleae sensu Merxmüller, Leins e Roessler (1977) era parafilética, uma vez que os 
representantes estavam inseridos em 3 subgrupos: Inuleae-Plucheinae s.l., Inulinae s. str. e Gnaphalieae. Posteriormente, Anderberg (1989) realizou outro estudo filogenético, também baseado em caracteres morfológicos, que subsidiou uma nova circunscrição da tribo Inuleae, segregando membros de Inuleae-Plucheinae s.l. em uma nova tribo, Plucheae (Benth.) A. Anderb., e restabelecendo a tribo Gnaphalieae Rydb. Estudos filogenéticos posteriores baseados em caracteres moleculares evidenciaram que Inuleae e Plucheae formam um grupo monofilético subordinado à subfamília Asteroideae (ANDERGERG et al., 2005; BAYER; STAR 1998; ELDENÄS; KALLESRJÖ; ANDERBERG, 1999; KIM; JANSEN, 1995; NYLINDER; ANDERBERG, 2015). Dessa forma, Anderberg e Eldenäs (2007) alteraram o status de Plucheae, posicionando-a como uma subtribo de Inuleae, sendo assim aceita até o presente.

A tribo Inuleae possui 66 gêneros e cerca de 690 espécies, com distribuição tropical, subtropical e temperada. A maioria das espécies da tribo ocorre na Eurásia, sul e leste da África (ANDERBERG; ELDENÄS, 2007), sendo a região mediterrânea considerada o centro de diversidade do grupo (ANDERBERG, 2009). Cerca de metade dos gêneros da tribo é monoespecífico ou possui 2 espécies. A circunscrição da tribo tem mudado muito nas últimas décadas e, atualmente, a tribo é caracterizada pela presença de ductos resiníferos no caule, ausência de ductos laticíferos, ausência de fibras no floema, antera com base caudada, ramos do estilete obtusos, pólen caveado e equinado, com exina microperfurada (ANDERBERG 2009; ANDERBERG; ELDENÄS 2007).

\section{Descrição}

Árvores, arbustos, subarbustos, ervas anuais ou perenes, monoicas, andromonoicas ou ginomonoicas; raízes fasciculadas, rizomatosas, tuberosas ou xilopodiais; ramos alados ou não, com ductos resiníferos. Folhas alternas, subopostas, lâminas inteiras, pinatífidas, ou pinatissectas, margens inteiras, serreadas ou denteadas, glabras ou com indumento. Capitulescência racemiforme, corimbiforme, paniculiforme, espiciforme, em glomérulo, capitulescência de segunda ordem, em racemo ou corimbo 
espiciforme, racemos de glomérulo, corimbo espiciforme ou de glomérulo ou capítulos solitários. Capítulos homógamos ou heterógamos, radiados, discoides ou disciformes; involucro multisseriado; receptáculo plano, convexo ou côncavo, paleáceo ou epaleáceo. Flores dimórficas, raramente isomórficas, e se dimórficas, flores do raio pistiladas ou neutras, unisseriadas ou plurisseriadas, corola ligulada, tubulosa ou tubuloso-filiforme, amarela, rósea, lilás, roxa ou branca; flores do disco bissexuais ou funcionalmente masculinas, corola tubulosa, amarela, rósea, lilás, roxa ou branca; anteras caudadas, ecalcaradas, raramente calcaradas, apêndices basais longos ou curtos, lineares, bífidos ou não; estilete bífido ou indiviso, em flores com gineceu abortado, superfície papilosa ou com tricomas pubescentes abaixo da ramificação. Cipselas elipsoides, turbinadas, costadas, glabras ou com indumento, células epidérmicas com ou sem cristais de oxalato de cálcio; pápus cerdoso e/ou escamoso, ou ausente.

A tribo Inuleae está representada no Brasil por 5 gêneros e 22 espécies ocorrendo nas províncias fitogeográficas da Amazônia, caatinga, cerrado, floresta atlântica, pampa e pantanal. O pampa é a província fitogeográfica com maior diversidade de espécies no país. Algumas espécies podem ocorrer em ambientes antropizados. Epaltes Cass. é um gênero com distribuição pantropical (ANDERBERG, 2009) e, no Brasil, possui uma única espécie, ocorrente em áreas úmidas, alagadas e à beira de riachos nas províncias do Amazonas, caatinga e pantanal; Pluchea Cass. possui distribuição cosmopolita (ANDERBERG, 2009), e as 3 espécies ocorrentes no Brasil estão dispersas no cerrado, floresta atlântica, pampa e também em ambientes antropizados (Figura 16G); Pterocaulon Elliot ocorre nas Américas e Australásia (CABRERA; RAGONESE, 1978), e, no Brasil, é o gênero que apresenta maior diversidade, com 11 espécies, e distribuição mais ampla, estando presente no cerrado, floresta atlântica brasileira, pampa, pantanal e áreas antropizadas (Figura $16 \mathrm{H})$; Stenachaenium Benth. é um gênero sul-americano restrito ao cone sul, e as 5 espécies do Brasil ocorrem no pampa (ANDERBERG, 2009) (Figura 16I); Tessaria Ruiz \& Pav. possui 2 espécies no Brasil, ambas na província do pampa (BFG, 2015). 


\section{Chave de identificação para os gêneros de Inuleae para o Brasil}

1. Pápus ausente Epaltes

1’. Pápus presente 2

2. Capítulos sésseis, capitulescência racemiforme, panículas espiciformes ou glomeruliformes Pterocaulon

2'. Capítulos pedunculados, organizados em capitulescência 3

3. Folhas basais em roseta; flores do disco bissexuais Stenachaenium

3'. Folhas basais alternas; flores do disco masculinas por aborto do gineceu 4

4. Caule alado; flores do disco numerosas, 25-50 por capítulo. Pluchea 4'. Caule cilíndrico (não alado); flores do disco poucas, 1-15 por capítulo..... Tessaria

\section{Literatura recomendada}

ANDERBERG, A. A. Inuleae. In: V.A. FUNK; A. et al. Systematics, Evolution, and Biogeography of Compositae. Viena: IAPT, 2009. p. 667-680.

ANDERBERG, A. A. Phylogeny and reclassification of the tribe Inuleae (Asteraceae). Canadian Journal of Botany, Ottawa, v. 67, n. 8, p. 2277-2296, 1989.

ANDERBERG, A. A.; ELDENÄS, P. Tribe Inuleae. In. KUBITZKI, K.;

KADEREIT, J. W.; JEFFREY, C. (Ed.). The Families and Genera of Vascular Plant: v. VIII: Flowering Plants Eudicots: Asterales. Berlin: Springer-Verlag, 2007. p. 374-391.

ANDERBERG, A. A. et al. Evolutionary relationships in the Asteraceae tribe Inuleae (Incl. Plucheae) evidenced by DNA sequences of ndhF, with notes on the systematic position of some aberrant genera. Organism, Diversity and Evolution, Jena, v. 5, n. 2, p. 135-146, 2005. 
BAYER, R. J.; STAR, J. R. The phylogeny of Asteraceae based on two noncodding chloroplast sequences, the trnL intron and $\operatorname{trnL} / \operatorname{trnF}$ intergenic spacer. Annals of the Missouri Botanical Garden, Saint Louis, v. 85, n. 2, p. 242-256, 1998.

BENTHAM, G. Compositae. In: BENTHAM, G.; J. D. HOOKER (Ed.). Genera Plantarum. London: Lovell Reeve, 1873. p 180-189.

BREMER, K. Tribal interrelationships of Asteraceae. Cladistics, Westport, v. 3, n. 3, p. 210-256, 1987.

CABRERA, A. L.; RAGONESE, A. M. Revisión del género Pterocaulon (Compositae). Darwiniana, v. 21, p. 185-257, 1978.

CASSINI, H. Suit du sixiéme mémoire sur la familie des Synanthérées, contenat les caractères des tribus. Journal de Physique, de Chimie, d'Histoire Naturelle et des Arts 88, Paris, p. 189-204, 1819.

CANDOLLE, A. de. Prodromus Systematis Naturalis Regni Vegetabilis. Paris: Treutel \& Würtz, 1836. Pars. 5.

ELDENÄS, P.; KALLESRJÖ, M.; ANDERBERG, A. A. Phylogenetic placement and circunscription Inuleae s.str. and Plucheae (Asteraceae): evidence from sequences gene ndhF. Molecular Phylogenetics and Evolution, Orlando, v.13, p. 50-58, 1999.

HOFFMANN, O. Compositae. In: ENGLER, A.; PRANTL, K. Die Natürlichen Pflanzenfamilien. Leipzig: W. Engelmann, 1890. v. 4, p. 87-391.

KIM, K. J.; JANSEN, R. K. ndhF sequence evolution and the major clades in the sunflower family. Proceedings of the National academy of Science of the United States of America, Washington, v. 92, n. 22, p. 10379-10383, 1995.

LESSING, C. F. Synopsis Generarum Compositarum. Berlin: Dunker \& Humboldt, 1832.

MERXMÜLLER, H.; LEINS, P.; ROESSLER, H. Inuleae-Systematic Review. In: HEYWOOD, V. H.; HARBONE, J. B.; TURNER, B. L. (Ed.). Biology and Chemestry of Asteraceae. London: Academic Press, 1977. p. 577-602.

NYLINDER, S.; ANDERBERG, A. A. Phylogeny of the Inuleae (Asteraceae) with special emphasis in Inuleae-Plucheainae. Taxon, Utrecht, v. 64, n. 1, p. 110-130, 2015. 

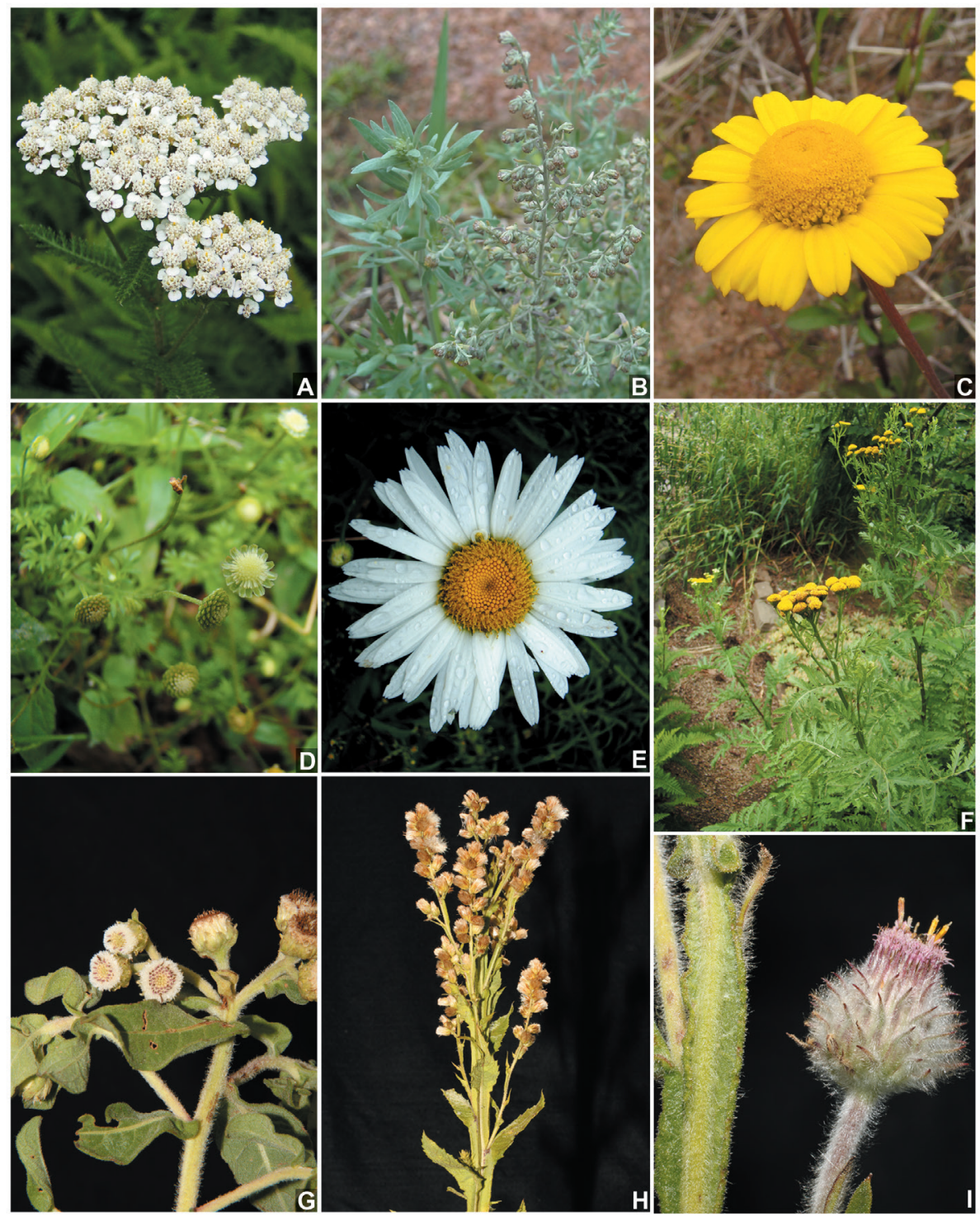

Figura 16. Anthemideae. A. Achillea millefolium L.; B. Artemisia sp.; C. Coleostephus myconis (L.) Cass.; D. Cotula australis (Sieber ex Spreng.) Hook. f.; E. Leucanthemum vulgare Lam.; F. Tanacetum vulgare L. Inuleae. G. Pluchea sagittalis (Lam.) Cabrera; H. Pterocaulon polystachyum DC.; I. Stenachaenium megapotamicum (Spreng.) Baker. 